\title{
EDITORIAL
}

\section{Debate on fast food in society}

International Journal of Obesity (2007) 31, 883;

doi:10.1038/sj.ijo.0803633

This issue of the journal has a debate by Rice et al. ${ }^{1}$ and Stender et $\mathrm{al}^{2}{ }^{2}$ that examines the role of fast foods in a diet that might be recommended to consumers. Rice et al. ${ }^{1}$ suggest that it is possible to create a diet eaten only in fastfood restaurants that is very close to the recommendations of the US dietary reference index. Rice et al. ${ }^{1}$ show that with the possible exception of the problem of trans fats, a fast-food diet can be constructed with good choices that is nutritionally complete and healthy, and there is no reason to avoid fast-food restaurants.

Stender et al. $^{2}$ counter that the average fast-food meal is more energy dense than is optimal and that the average consumer would not have the nutrition skills to fashion a healthy fast-food menu. In addition, these authors note that the nutrient content (particularly fat) of meals in fast-food restaurants differs greatly across the world. Finally, many fast foods contain large amounts of trans fatty acids, which are thought to have no role in the diet of modern individuals.

Defenders of individual freedom will note that fast-food restaurants are presenting the food items that consumers want to eat and that it is an individual's responsibility to devise a healthy menu of all food items eaten that over time would average out the fast-food 'indulgence.' The assertion by Stender et al. ${ }^{2}$ that restaurants should provide menus that are composed of lean meat burgers, low-fat condiments, etc., ignores the fact that consumers do not buy 'healthy' items such as lean burgers. When such items have been added to menus of fast-food restaurants, their slow sales resulted in their removal from the menu.

Individuals who have a more activist, governmental orientation call for 'twinkie taxes' and note that the end result of unhealthy fast-food availability is a society that is less healthy and that has higher health costs. Specifically, there seems to be no reason other than convenience to merchants to have a high trans fat content of meals. It is noteworthy that the figure of Stender et al. ${ }^{2}$ shows that the highest contents of trans fats appear most often in restaurants of highly developed countries where the convenience and shelf-life associated with trans fats is not critical.

The current environment has been called a 'toxic environment' because of the easy availability of energy-dense, tasty food, the increasing worldwide prevalence of fast-food restaurants, and the increasing removal of the necessity to do physical activity. Use of the term 'toxic' to describe fast foods and the environment is not helpful to the debate and is not scientifically rigorous. A better term would be an 'obesogenic environment' because it is descriptive and not pejorative. There is no question the environment is 'obesogenic' because more than adequate food is available in almost all countries of the world, and one consequence is the increasing epidemic of obesity worldwide.

The debate about fast foods raises fundamental questions about individual choices and individual responsibility that will have to be faced by societies across the world. The level of governmental intervention certainly will differ among nations. The lesson from this debate is that eating a healthy fast-food meal will require educating consumers and pressurizing manufacturers to have accurate nutrition information posted in restaurants of different countries that are specific for individual countries and type of restaurants.

RL Atkinson ${ }^{1}$ and I Macdonald ${ }^{2}$
${ }^{1}$ Obetech Obesity Research Center, Richmond, VA, UK and
${ }^{2}$ University of Nottingham Medical School, School of Biomedical
Sciences, Queen's Medical Centre, Nottingham, NG, UK
E-mail: ratkinson2@vcu.edu

\section{References}

1 Rice S, McAllister EJ, Dhurandhar NV. Fast food. Friendly? Int J Obes Relat Metab Disord this issue.

2 Stender S, Dyerberg J, Astrup A. Fast-food: Unfriendly and unhealthy. Int J Obes Relat Metab Disord this issue. 